\title{
6. EXTRACURRICULAR EDUCATION AND EDUCATION IN THE REPUBLIC OF MOLDOVA. CONTEXT: SOCIAL, POLITICAL, ECONOMIC, EDUCATIONAL
}

Marina Cosumov $^{253}$

\begin{abstract}
Education in contemporary society is a strategic resource for sustainable human development, in a space and time determined from a historical, political, cultural, socioeconomic point of view, etc. Lifelong learning has become a fundamental requirement of society under these conditions. Learning to learn and wanting to continually improve are requirements of lifelong learning; responding to them, man learns to be receptive to change, able to anticipate and adapt to them, offering himself as a participant in the process of social evolution due to his intellectual and moral autonomy. The design, organization, functioning and development of the education system in the Republic of Moldova aims at the complementary quality of extracurricular education that takes place in educational institutions and aims to develop the cognitive, affective and action potential of children and young people, to respond to their interests and options for free and its ability to provide additional opportunities for information, documentation, communication, development, social inclusion and self-realization.
\end{abstract}

Key words: education system, lifelong learning, education / extracurricular education, educational context

\section{Introduction}

Education (formal, non-formal, informal) encompasses values and resources designed to teach students how to learn and how to integrate socio-culturally. An important role in this register is played by educational institutions, the family, religious, cultural and artistic institutions, museums, media, houses of culture, etc. The ever-changing society, determined by the exponential growth of information and its accelerated wear, by the extraordinary advances of science, technology, by the dynamism of social life, by the democratization of learning, by the increase of the level of aspiration towards culture and education. more pleasant leisure time also generates new demands on education, and man in turn must be continuously as a recipient of educational action.

Formal education (from the Latin "formalis" - form, figure, model, legally organized, formal) refers to all systematic and organized educational actions, developed and carried out in specialized educational institutions (school, university, etc.).

Informal education (from the Latin "informalis" - without form) refers to the totality of unorganized, unsystematic and non-subordinate educational influences to precise educational purposes.

Non-formal education is defined as any personal or social education program, designed to improve certain skills outside the formal curriculum, or to carry out certain educational activities organized outside the compulsory education system, respectively proposed by various educational institutions. Non-formal

${ }^{253}$ Associate Professor PhD., „Alecu Russo” State University from Bălţi, Republic of Moldavia, email: cosumov@mail.ru 
education aims, among other things, to broaden the horizon of knowledge of the population, to create optimal conditions for personal and / or professional perfection of the individual, or his initiation into a new field of knowledge, to contribute to recreation and relaxation of the person, such as and to spend leisure time in an organized and enjoyable manner, to provide an adequate framework for skills training and talent demonstration, etc. [2, p.113].

\section{Discussions}

Although etymologically "nonformalis" means "outside any form of activity", non-formal education is not synonymous with "lack of education", but rather designates a less formalized educational reality, but with strong formative valences. -educational. In this sense, for the successful implementation of nonformal education it is necessary to respect some theoretical-methodological requirements, such as: ensuring the voluntary nature of involvement in the activity, creating various contexts in which to circulate a flexible information content, focusing on who learns, recording the objectives and contents in special documents and adapting them according to the psycho-individual characteristics of the participants, making the most of the experience of these people, their active and conscious involvement in the learning act, evaluating progress including complementary strategies, without giving necessary, of some official marks or qualifications, but with emphasis on the formative dimension of the acquired competencies, etc. All these elements make non-formal education an extremely important form of education for the development of the human being, which, in fact, respects the same didactic rigors as in the case of formal education, but which has a much more flexible and customized to the needs of the individual (.....).

Non-formal education includes all actions and educational influences structured, organized and institutionalized, but carried out outside the education system. Extracurricular education designates a less formalized educational reality, but also with formative effects, favoring the preoccupation of the field by ensuring a productive continuity and by following an evolution and succession from a teleological perspective of the process of independent affirmation in its correlation with educational values everywhere.

The evolution of extracurricular education in the Republic of Moldova circumscribes the first formations that appeared initially, during the 1950s, as a basis for the instructive activity of children's and youth organizations and transformed, in the 1970s, into extracurricular institutions with instructiveeducational, methodical and organizational functions. The units in question later asserted themselves as an integral part of the current education system. In recent decades, extracurricular education is carried out in public and private extracurricular institutions (centers, palaces, creative houses, technical-scientific creative clubs, centers for young tourists, centers for young naturalists, recreational sports schools, etc.).

Extracurricular education is a component part of the education system in the Republic of Moldova and a form of education regulated by: the Education Code of the Republic of Moldova (2014); Recommendation no.1437 on non-formal 
education of the Parliamentary Assembly of the Council of Europe (2000); Recommendation on the validation of non-formal and informal learning (Brussels, COM, 2012); Memorandum on Lifelong Learning (2000); other policy documents in the field of extracurricular (non-formal) education and training. In the context of these national and international documents, the development of education and extracurricular education is becoming a priority and a strategic direction for ensuring the quality of education. One of the main medium-term policy priorities is the diversification and intensification of extracurricular education, in the context of developing and implementing the national program for extracurricular education aimed at achieving the function of developing the vocation, creativity and entrepreneurship of young generations.

Access to activities carried out by public extracurricular institutions is free and open to all applicants between the ages of 5 and 21, except for arts / music / sports schools, offering everyone equal opportunities for multilateral development and self-determination in the field of leisure. The key-concept of extracurricular (non-formal) education is to achieve the function of extension and complementarity in relation to formal education. This function is achieved through two directions: activities organized outside the classroom: circles, competitions, Olympics, competitions, cultural and artistic events, etc .; activities organized outside the general education school: excursions, visits, camps, exhibitions, creative centers; extracurricular (non-formal) educational institutions of artistic, sports, etc. profile. By its nature and specificity, extracurricular education attests its own characteristics, among which:

- variety of forms and contents,

- differentiation of activities,

- forms of organization, etc.

It is about satisfying education in better and more varied conditions, through the same formative influences, but from inter-, multi- and transdisciplinary perspectives, one of the most important premises for choosing extracurricular activities related to the impact that extracurricular education has on the development of the trainee's personality. It is considered that the effects of education and extracurricular education are beneficial for the development of the trainee's personality, contributing to the optimization of learning outcomes, to the increase of activism and the process of involvement in various institutional and community activities, etc. An important factor for motivating trainees to participate in extracurricular activities is related to the psycho-pedagogical experience of teachers, providers of extracurricular educational services.

Starting from the concept and specificity of the characteristics of extracurricular education, but also from the content and methodological options for carrying out this process, the structure of extracurricular education and teaching has been outlined, which consists of specific fields, profiles and types of activities / disciplines (Figure 1): 


\section{The fields of education and extracurricular education in the Republic of Moldova}

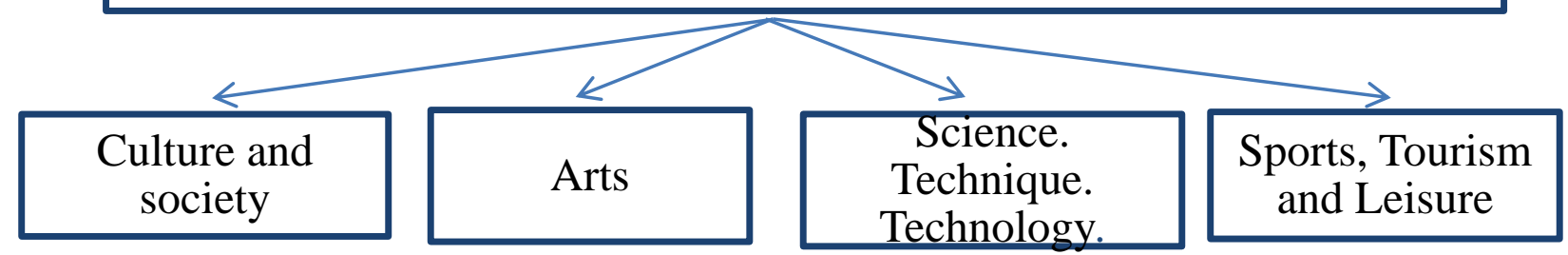

Fig. no.1. The fields of education and extracurricular education in the Republic of Moldova

The prospectiveness of extracurricular education involves its relation to the perspective requirements of society, by orienting the providers of extracurricular education to a new way of education, which will ensure the individual the opportunity to cope with unforeseen events by anticipation and participation. The permanent character of extracurricular education imposes the need for educational influences at all stages of ontogenetic development. The constantly changing society generates new demands on education, in general, in which the individual is permanently as a receiver and agent of educational action. Educational success is determined by favorable biopsychic premises and stimulating social environment, education being the decisive factor in the formation / development of personality $[3$, p. 86].

True learning is always a meaning-generating process. Understanding this brings to the fore a new way of learning, which ensures human development, able on a personal level - through reflection, understanding, creativity, rational choice to acquire knowledge, skills and competencies to solve vital everyday problems. Modern pedagogical science treats the instructive-educational process as a special process organized and instrumented from the point of view of didactic technologies, the essence of which is to create favorable conditions for each individual to form the necessary skills for continuous development and improvement [4, p. 89].

\section{Results}

Analyzing different approaches and models of education, including extracurricular education, we extrapolate a system of general laws on extracurricular education and teaching, namely:

1. The aims, character and content of education and extracurricular education are determined by the objective needs / interests of the student, by the sociocultural and ethical norms and values;

2. The aims of education and extracurricular education are determined by the correspondence of pedagogical influences with objective and subjective factors;

3. The positive reaction of the student to the pedagogical influences is determined by the needs, necessities, interests and possibilities of the educable, focusing on the creation of the optimistic perspectives of the personal / individual development;

4. The efficiency of education and extracurricular education are determined by the 
level of activism of the student, by his performances / successes, but also by the content and applied educational technologies, by the reasons for participating in the activity.

The specific laws underlying education and extracurricular education in the Republic of Moldova point out:

1. The educational process has a determined teleological, motivational character, it is intact and bipolar;

2. The process of personality formation-development cannot take place without its active participation in this process;

3. The development of a person's skills is interconnected and interdetermined. In the real process of personality formation these competencies are manifested in different combinations;

4. The components of the educational process are not equal in relation to each other, there is a submission, an interconnection between them: penetrating into each other, in the most diverse combinations, they constitute a unique / integrated educational process [5, p.43].

The content of education and extracurricular education creates premises for the realization of individual programs that capitalize on the effects of non-formal education generated by the social environment. This curricular perspective gives the content of extracurricular education a character, equally stable and dynamic: stable, through the educational values of maximum formative efficiency; dynamic, through specifications and concretizations in relation to the fields and profiles of extracurricular education and in relation to the interests, skills, opportunities of learners.

\section{Conclusions}

Therefore, the content of extracurricular education and teaching defines the set of selected values from all fields of culture and human activity, in terms of knowledge with maximum formative effects - intellectually, morally, technologically, aesthetically, physically, cognitively, effectively, psychomotor processed at the level of areas, profiles and concrete contexts of extracurricular education and teaching. The transposition of these positions / approaches into conceptual, methodological and praxiological provisions as a result of the longterm developments and transformations of the non-formal / extracurricular educational process will ensure the functionality of the extracurricular education and teaching system in the Republic of Moldova.

\section{References}

1. Blândul Valentin, Bazele educaţiei nonformale, Editura MEGA, Cluj-Napoca, 2015

2. Callo Tatiana, O pedagogie a integralităţii, Editura CEP USM, Chişinău, 2007

3. Cristea Sorin, Fundamentele pedagogiei, Editura Polirom, Iaşi, 2010

4. Cucoş Constantin, Educaţia estetică , Editura Polirom, Iaşi, 2014

5. Guţu Vladimir, Posţan, L., Didactica pentru adulţi din perspectiva motivaţională, Editura CEP USM, Chişinău, 2007

6. Dave Rodgers, Fundamentele educaţiei permanente, Editura Humanitas, Bucureşti, 1991 